\title{
Role of CD8 + T Cells in Endogenous Interleukin-10 Secretion Associated with Visceral Leishmaniasis
}

\author{
Bettie J Holaday \\ Núcleo de Medicina Tropical, Universidade Federal do Ceará, Rua Alexandre Baraúna 949, 60430-160 \\ Fortaleza, CE, Brasil
}

This study examined the role and source of endogenous interleukin-10 (IL) secretion in visceral leishmaniasis (VL). The amounts of endogenous and Leishmania specific IL-10 and interferon- $\gamma($ IFN) secreted by peripheral blood mononuclear cells (PBMC) from VL patients were compared. The correlation coefficient between endogenous IL-10 secretion and Leishmania specific IFN- $\gamma$ was -0.77 , suggesting a major role for endogenous $I L-10$ secretion in $V L$. The effects of $C D 4+$ and $C D 8+T$ cell clones, isolated from a treated VL patient, on IL-10 secretion were assayed by mixing the clones with autologous, inactivated PBMC. The CD8+ clones mediated increased levels of IL-10 secretion in the presence of PBMC alone suggesting that CD8+ T cells may mediate endogenous IL-10 secretion.

Key words: leishmaniasis - T2 CD4+ - T2 CD8+ - CD8+ Ts - endogenous interleukin-10

Visceral leishmaniasis (VL) is characterized by inability of the hosts' macrophages to kill intracellular amastigotes. Failure of CD4+ T cells to secrete significant amounts of macrophage activating cytokines, such as interferon- $\gamma$ (IFN), in response to Leishmania antigens plays a major role in this immunopathology (Murray et al. 1983, Carvalho et al. 1985). Elevated levels of interleukin-10 (IL) secretion occur in some visceral leishmaniasis patients (Karp et al. 1993, Ghalib et al. 1993, Holaday et al. 1993). Cultures of peripheral blood mononuclear cells (PBMC) isolated from VL patients have shown that elevation of either endogenous or antigen specific IL-10 secretion or both can occur (Gasim et al. 1998, Holaday 1999). Increased IL-10 secretion is thought to be an important element in the immunopathology of VL since it is a potent inhibitor of macrophage activation in general and IFN- $\gamma$ secretion in particular (Mossman \& Moore 1991, Howard \& O'Garra 1992). This study provides further evidence that CD8+ T cells mediate endogenous IL-

\footnotetext{
This work was supported by United States National Institutes of Health grants 5PO1 AI-26512 and AI-26918 and TDR Strengthening Grant 880-225.

Present address: 170A Grattan St., San Francisco, CA 94117, USA. Fax: +1-415-566-9776.

Received 7 May 1999

Accepted 26 November 1999
}

10 secretion and that endogenous IL-10 secretion is important in the immunopathology of VL.

The correlation of endogenous and antigen specific IL-10 secretion with antigen specific IFN- $\gamma$ secretion was determined for PBMC from 19 acute and five treated VL patients using methods described previously (Holaday 1999). PBMC from one of the patients were assayed twice, once three days after initiation of treatment and a second time seven days later. Peripheral blood was collected by venipuncture and mononuclear cells were separated by centrifugation at $200 \mathrm{~g}$ for $20 \mathrm{~min}$ at $20^{\circ} \mathrm{C}$ over ficoll-hypaque. Cells were washed twice in Hank's balanced salt solution containing $0.25 \%$ bovine serum albumin. The washed cells were cultured at $3 \times 10^{6}$ cells $/ \mathrm{ml}$ in Iscove's modified Dulbecco's medium supplemented with $10 \%$ fetal calf serum $/ 10 \%$ human $\mathrm{AB}+$ serum and containing antibiotic/antimycotic in the absence or presence of $20 \mu \mathrm{g} / \mathrm{ml}$ Leishmania antigens. Supernatants were collected on day 4 and stored frozen prior to assay. Levels of IL-10 in the supernatants were determined using commercially available monoclonal anti-human IL-10, anti-human IL-10biotin, rhIL-10 (Pharmingen, San Diego, CA) and extravidin peroxidase (Sigma) according to Pharmingen's procedure. This Elisa is sensitive to $20 \mathrm{pg} / \mathrm{ml}$. Levels of IFN- $\gamma$ were measured using a commercially available human IFN- $\gamma$ Elisa kit (Genzyme, Cambridge, MA). The kit is sensitive to at least $100 \mathrm{pg} / \mathrm{ml}$. PBMC from seven acute patients secreted insignificant amounts of IL-10 in the presence $(0.09 \pm 0.06 \mathrm{ng} / \mathrm{ml})$ and absence of 
antigens $(0.07 \pm 0.06 \mathrm{ng} / \mathrm{ml})$. PBMC from the same patients also secreted insignificant amounts of IFN- $\gamma$ in the presence $(0.02 \pm 0.04 \mathrm{ng} / \mathrm{ml})$ and absence $(0 \pm 0 \mathrm{ng} / \mathrm{ml})$ of antigens. PBMC from these seven low activity patients were not analyzed further in this study. PBMC in the remaining 13 assays exhibited levels of endogenous or antigen specific IL-10 secretion which were greater than two standard deviations above zero. Endogenous levels of IL-10 secretion for these patients formed a continuum from $0-1.32 \mathrm{ng} / \mathrm{ml}$, as shown in Fig. 1 arranged in order of level of endogenous IL-10 secretion. The lower half of the figure shows the levels of IFN- $\gamma$ secretion for the corresponding patients. The correlation coefficient between endogenous IL-10 secretion and antigen specific IFN- $\gamma$ secretion was -0.77 while that between antigen specific IL-10 secretion and antigen specific IFN- $\gamma$ secretion was -0.04 . PBMC secreting less than approximately $0.5 \mathrm{ng} / \mathrm{ml}$ of endogenous IL10 secreted additional IL-10 when exogenous antigen was added while PBMC which secreted more than approximately $0.5 \mathrm{ng} / \mathrm{ml}$ secreted less IL-10 when exogenous antigen was added or the level remained the same. Levels of IL-10 and IFN- $\gamma$ secretion by PBMC from the five treated patients are also shown in Fig. 1. While the average IL-10 secretion levels were lower and the average IFN- $\gamma$ secretion levels were higher than those of acute patient PBMC the values overlapped the acute patient levels. The correlation coefficient between endogenous IL-10 secretion and antigen specific IFN- $\gamma$ secretion was lower for treated patients, -0.48 .

The high correlation coefficient between endogenous IL-10 secretion and antigen specific IFN- $\gamma$ secretion by acute patient PBMC suggests that endogenous IL-10 secretion has a major role in the immunopathology of VL. The lack of correlation between antigen specific IL-10 secretion and IFN- $\gamma$ secretion by the same PBMC suggests that antigen specific IL-10 secretion is less important in the immunopathology of VL. These findings are in agreement with those of Gasim et al. (1998) who found that high levels of endogenous IL-10 secretion correlated with greater splenomegaly, more frequent hepatomegaly, and progression to post-kala-azar dermal leishmaniasis. Variation in levels of endogenous IL-10 secretion may explain the variable cellular immune responses of VL patients. High levels of endogenous IL-10 secretion might inhibit cellular immune responses to many antigens and mitogens, rather than to Leishmania antigens alone, resulting in anergy to multiple antigens and PHA as observed in some VL patients (Aikat et al. 1979, Ghose et al. 1979, Ho et al. 1983). Low levels of endogenous IL-10 se-
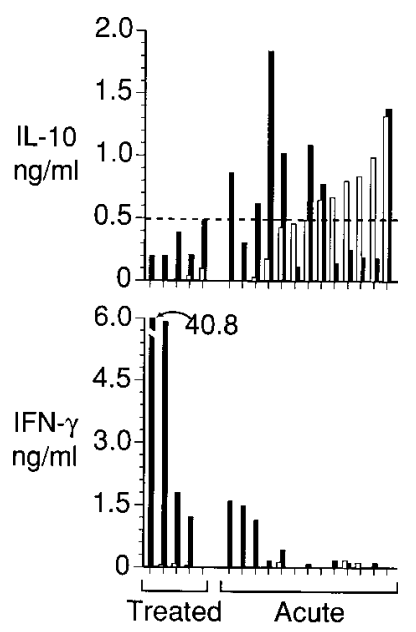

Fig. 1: interleukin-10 (IL) and interferon- $\gamma$ (IFN- $\gamma$ ) secretion by peripheral blood mononuclear cells from acute and treated visceral leishmaniasis patients in the absence (white bars) or presence (black bars) of Leishmania antigens. The dotted line through $0.5 \mathrm{ng} / \mathrm{ml}$ represents the level of endogenous IL-10 secretion associated with decreased antigen specific IL-10 secretion.

cretion accompanied by high levels of antigen specific IL-10 secretion might result in anergy to Leishmania antigens alone, as observed in other VL patients (Carvalho et al. 1981, Haldar et al. 1983). The data also support the hypothesis that IL-10 secretion is regulated, in part, by Leishmania antigens (Holaday 1999). When endogenous IL-10 secretion reached approximately $0.5 \mathrm{ng} / \mathrm{ml}$, addition of Leishmania antigens appeared to trigger a regulatory mechanism which decreased both endogenous and antigen specific IL-10 secretion. Failure of this mechanism may be critical in the prognosis of VL patients since the ability to recover from VL might be compromised by uncontrolled IL-10 secretion.

The role of CD4+ and CD8+ T cells in endogenous and antigen specific IL-10 secretion was examined by assaying $10 \mathrm{CD} 4+$ and six CD8+ T cell clones isolated from a treated patient. PBMC from a treated patient were used as the source of the clones because both CD4+ and CD8+ T cell clones can be isolated from the same individual during the same cloning procedure (Holaday et al. 1993). The clones were derived as previously described from PBMC stimulated with antigen. PBMC surviving two weeks after the initial antigen stimulation were stimulated twice more at $5 \mathrm{x}$ $10^{5} / \mathrm{ml}$ by antigen presented by $10^{6} / \mathrm{ml}$ thawed, gamma-irradiated (3,000 rad), autologous PBMC. The cells were analyzed for percentage of CD4+ and CD8+ cells by immunofluorescence, serially diluted to $0.5 \mathrm{CD} 4+$ cells/well, and stimulated by 
$5 \mu \mathrm{g} / \mathrm{ml} \mathrm{PHA}$ and $25 \mathrm{U} / \mathrm{ml} \mathrm{rIL-2}$ in the presence of $10 \% \mathrm{ml}$ gamma-irradiated $(4,000 \mathrm{rad})$, allogeneic PBMC and $10^{5} / \mathrm{ml}$ mitomycin c treated $(50 \mu \mathrm{g} / \mathrm{ml}$ for $45 \mathrm{~min}$ ), gamma-irradiated (2,000 rad) JY cells as feeders. When clones appeared in the wells they were expanded by the same stimulation method until sufficient numbers of cells were present for assays of activity. The 16 best growing clones were analyzed for CD4 and CD8 surface markers and cytokine secretion. The clones were assayed at 2 x $10^{5} / \mathrm{ml}$ with or without autologous, irradiated PBMC at $2 \times 10^{6} / \mathrm{ml}$ in the presence or absence of $20 \mu \mathrm{g} / \mathrm{ml}$ Leishmania antigen. Supernatants were collected on day 4 and analyzed for levels of IL10 and IFN- $\gamma$. Three of 10 CD4+ T cell clones secreted significantly more IL-10 in response to Leishmania antigens presented by inactivated PBMC than in the absence of antigens (Fig. 2). One of the three clones also secreted significant IL-10 in the presence of inactivated PBMC alone. All six CD8+ clones secreted significant levels of IL-10 in the presence of inactivated PBMC alone which decreased significantly when antigen was added. The clones alone did not secrete IL-10. None of the CD4+ or CD8+ clones secreted levels of IFN- $\gamma$ above that secreted by inactivated PBMC alone.

The fact that all six of the CD8+ T cell clones assayed mediated increased levels of IL-10 in the presence of inactivated PBMC alone indicates that the CD8+ cells responded to PBMC subpopulations themselves. Addition of antigen decreased this level significantly, similar to the effect of antigen on endogenous IL-10 secretion by acute patient PBMC. Only one of the $10 \mathrm{CD} 4+$ clones secreted significant amounts of IL-10 in response to inactivated PBMC alone, suggesting that CD8+ T cells are more likely to mediate endogenous IL-10 secretion than CD4+ T cells. Three of the $10 \mathrm{CD} 4+$

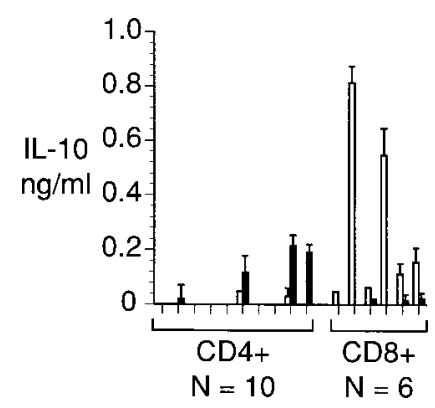

Fig. 2: interleukin-10 (IL) secretion by $\mathrm{CD} 4+$ or $\mathrm{CD} 8+\mathrm{T}$ cell clones in the presence of autologous irradiated peripheral blood mononuclear cells from a treated visceral leishmaniasis patient in the absence (white bars) or presence (black bars) of Leishmania antigens. clones secreted IL-10 in response to Leishmania antigens, suggesting that CD4+ T cells are responsible for antigen specific IL-10 secretion.

These data must be interpreted with caution for two reasons. First, the cells responsible for actual IL-10 secretion in these assays cannot be identified with certainty, since the T cell clones may have secreted IL-10 themselves or induced PBMC subsets to secrete IL-10. Previous studies have shown that IL-10 may be secreted by B cells and mononuclear phagocytes, as well as by T cells (Howard \& O'Garra 1992, Gasim et al. 1998). Second, the $\mathrm{T}$ cell clones were all derived from a single treated patient and may not be representative of acute patients' or even of other treated patients' $\mathrm{T}$ cells. However, if the same CD4+ and CD8+ T cell subsets are present in acute patients and mediate antigen specific and endogenous IL-10 secretion, respectively, it suggests that immunodominance of the CD8+ $\mathrm{T}$ cells plays an important role in progressive VL while the role of the CD4+ T cells is less apparent.

\section{REFERENCES}

Aikat BK, Pathania AGS, Sehgal S, Bhattacharya PK, Dutta U, Pasricha N, Singh S, Parman RS, Sahaya S, Prasad LSN 1979. Immunological responses in Indian kala-azar. Indian J Med Res 70: 583-591.

Carvalho EM, Badaró R, Reed SG, Jones TC, Johnson WD 1985. Absence of gamma interferon and interleukin 2 production during active visceral leishmaniasis. J Clin Invest 76: 2066-2069.

Carvalho EM, Teixeira R, Johnson WD 1981. Cellmeiated immunity in American visceral leishmaniasis: Reversible immunosppression during acute infection. Infect Immun 33: 498-502.

Gasim S, Elhassan AM, Khalil EAG, Ismail A, Kadaru AMY, Kharazmi A, Theander TG 1998. High levels of plasma IL-10 and expression of IL-10 by keratinocytes during visceral leishmaniasis predict subsequent development of post-kala-azar dermal leishmaniasis. Clin Exp Immunol 111: 64-69.

Ghalib H, Piuvezam M, Skeiky Y 1993. Interleukin 10 production correlates with pathology in human Leishmania donovani infections. J Clin Invest 92: 324-329.

Ghose AC, Haldar JP, Pal SC, Mishra BP, Mishra KK 1979. Phytohaemagglutinin-induced lymphocyte transformation test in Indian kala-azar. Trans $R$ Soc Trop Med Hyg 73: 725-726.

Haldar JP, Ghose S, Saha KC, Ghose AC 1983. Cellmediated immune response in Indian kala azar and post-kala azar dermal leishmaniasis. Infect Immun 42: 702-707.

Ho M, Koech DK, Iha DW, Bryceson ADM 1983. Immunosuppression in Kenyan visceral leishmaniasis. Clin Exp Immunol 51: 207-214.

Holaday BJ 1999. Immunotherapy for visceral leishmaniasis: Ability of factors produced during anti-leishmania responses of skin test positive adults to inhibit peripheral blood mononuclear cell activities 
associated with visceral leishmaniasis. Mem Inst Oswaldo Cruz 94: 55-66.

Holaday BJ, Pompeu MM, Jeronimo S, Texeira MJ, Sousa AQ, Vasconcelos AW, Pearson RD, Abrams JS, Locksley RM 1993. Potential role for interleukin10 in the immunosuppression associated with kala azar. J Clin Invest 92: 2626-2632.

Howard M \& O'Garra A 1992. Biological properties of interleukin 10. Immunol Today 13: 198-200.

Karp CL, El-Safi SH, Wynn TA, Satti MMH, Kordofani AM, Hashim FA, Hag-Ali M, Neva FA, Nutman TB,
Sacks DL 1993. In vivo cytokine profiles in patients with kala-azar: Marked elevation of both interleukin10 and interferon-gamma. J Clin Invest 91: 16441648.

Mossman TR, Moore KW 1991. The roles of IL-10 in crossregulation of Th1 and Th2 responses. Immunol Today 12: A49-A53.

Murray HW, Rubin BY, Rothermel CD 1983. Killing of intracellular Leishmania donovani by lymphokinestimulated human mononuclear phagocytes. J Clin Invest 72: 1506-1510. 